\title{
Enhancing the roles of information and communication technologies in doctoral research processes
}

\author{
Sarah J. Stein ${ }^{1 *}$ (D) and Kwong Nui Sim²
}

\author{
*Correspondence: sarah.stein@ \\ otago.ac.nz \\ ${ }^{1}$ Distance Learning, University of \\ Otago, Dunedin, New Zealand \\ Full list of author information is \\ available at the end of the article
}

\begin{abstract}
While information and communication technologies (ICT) are prominent in educational practices at most levels of formal learning, there is relatively little known about the skills and understandings that underlie their effective and efficient use in research higher degree settings. This project aimed to identify doctoral supervisors' and students' perceptions of their roles in using ICT. Data were gathered through participative drawing and individual discussion sessions. Participants included 11 students and two supervisors from two New Zealand universities. Focus of the thematic analysis was on the views expressed by students about their ideas, practices and beliefs, in relation to their drawings. The major finding was that individuals hold assumptions and expectations about ICT and their use; they make judgements and take action based on those expectations and assumptions. Knowing about ICT and knowing about research processes separately form only part of the work of doctoral study. Just as supervision cannot be considered independently of the research project and the student involved, ICT skills and the use of ICT cannot be considered in the absence of the people and the project. What is more important in terms of facilitating the doctoral research process is students getting their "flow" right. This indicates a need to provide explicit support to enable students to embed ICT within their own research processes.
\end{abstract}

Keywords: Doctoral research and supervision, Information and communication technologies, Participative drawing

\section{Background/context}

Information and communication technologies (ICT) can bring either joy or challenge to well-versed academic practices, and either create barriers to learning and development or be the answer to needs. While some grasp and pursue opportunities to make use of various ICT for study, research and teaching, others struggle. Despite documented and anecdotal positive urges to adopt ICT to increase and improve efficiency and effectiveness, staff and students struggle experience ICT as needless and difficultto-use interruptions. There is often little need seen to change practices by introducing ICT into ways of working. Exploring these views and experiences was the focus of this project. Being empathetic to views such as those expressed by Castañeda and Selwyn

(c) The Author(s). 2020 Open Access This article is licensed under a Creative Commons Attribution 4.0 International License, which permits use, sharing, adaptation, distribution and reproduction in any medium or format, as long as you give appropriate credit to the original author(s) and the source, provide a link to the Creative Commons licence, and indicate if changes were made. The images or other third party material in this article are included in the article's Creative Commons licence, unless indicated otherwise in a credit line to the material. If material is not included in the article's Creative Commons licence and your intended use is not permitted by statutory regulation or exceeds the permitted use, you will need to obtain permission directly from the copyright holder. To view a copy of this licence, visit http://creativecommons.org/licenses/by/4.0/. 
(2018), we did not approach this investigation from a position that assumes that ICT are natural and needed solutions to problems related to improving and facilitating effective learning, teaching and research. Rather, we took a more neutral stance, wishing to explore the experiences of those involved, namely, students and staff, through discussion with them about their ICT practices and views, and with a specific focus on doctoral study and supervision.

\section{Rationale}

Doctoral supervision and the role, place and nature of the doctorate are receiving increasing attention in higher education research literature. A wide range of topics have been covered from, for example, the importance and types of support for students throughout candidature (e.g., Zhou \& Okahana, 2019); to the teaching and supervision aspects of doctoral supervision (e.g., Åkerlind \& McAlpine, 2017; Cotterall, 2011; Lee, 2008).

With advancements in, accessibility to, and development of, ICT within education settings has come a plethora of research into online and blended learning. These studies often highlight the capacity of ICT for facilitating teaching, learning and administrative activity within educational institutions and systems (e.g., Marshall \& Shepherd, 2016). They cover numerous areas of importance from theoretical, practical, and philosophical angles and include the perspectives and needs of learners, educators and institutions (e.g., Nichols, Anderson, Campbell, \& Thompson, 2014).

There are also studies on student use of ICT, though not necessarily doctoral students, and these cover a wide range of topics including specific ICT skills (e.g., Stensaker, Maassen, Borgan, Oftebro, \& Karseth, 2007). Where postgraduate research students are concerned, some studies on ICT skill development and support provide some insights about students (e.g., Dowling \& Wilson, 2017), and institutional ICT systems (Aghaee et al., 2016).

Notable about the many of these studies cited above is the use of self-reporting tools as mechanisms for gathering data about student use and views about ICT. While self-reports are valuable ways to collect such data about self-efficacy, they do have limits. In online learning environments, the role of self-efficacy, for example, is still being contested. It has been argued that learners from a variety of disciplines and learning settings will tend to overestimate claims about their performance and/or knowledge and skills (e.g., Mahmood, 2016).

All these studies help to 'map the territory' of ICT, their use at individual and institutional levels and related practices. Much advice and guidance can be gleaned from the literature as well, although relatively little for the specific integration of ICT within the doctoral research and supervision environment. Based on the literature that is available though, all indications are that (doctoral) students adopt educational practices incorporating limited ICT use, even though the use of ICT has grown enormously in the last 10 to 20 years. With the current interest in ensuring success of students and completion of doctoral degrees being closely related to high quality supervision, there is a need to improve supervision practices and within that, advance understandings about how to support students in their use of ICT for their doctoral research.

\section{This project}

This project aimed to explore doctoral student and supervisor views and use of ICT within the doctoral process. The intention was to bring to light perceptions that could 
give clues as to how to make practical modifications to the content and scope of professional development support for supervisors and students, in order to help them to make best use of ICT. In addition, consideration was given to the way data would be collected to ensure that more than just the self-reported perspectives of the participants were included.

An interpretivist research approach (Erickson, 2012) framed this study to support a focus on understanding the world from the perspectives of those who live it. Thus, the approach was well-suited to exploring perceptions about the use of ICT in our context.

Thus, this study did not commence with any hypotheses related to the influence of ICT in doctoral research in mind. Instead, as the interpretive frame of the research implies, this study investigated ways in which participants expressed their experiences of engaging and integrating ICT in support of their doctoral research processes. The data tapped into the participants' (PhD students and doctoral supervisors) perspectives, as they expressed them. The research approach thus defined and shaped all aspects of the data gathering, analyses and presentation. In this way, alignment was ensured among the ontological, epistemological and practical implementation of the research project.

\section{Setting}

The study took place in two New Zealand universities where participants were either employees or students. Both universities are research-intensive, with histories of producing high-level research across many disciplines. Both institutions have clear and wellformulated policies and practices governing doctoral study - $\mathrm{PhD}$ and professional doctorate - and these include supporting that study through supervision. A specialised unit in each institution manages the administration of the doctoral degree. Couching "supervision" as essentially a (specialised) teaching activity, each unit also provides or coordinates professional development for staff in the art of supervision, and for students in the skills and processes of undertaking doctoral degree study.

\section{Participants}

Participants included doctoral students and supervisors from the two universities. As a result of an invitation to all students and supervisors, in total, 11 students and two supervisors responded. The students were $\mathrm{PhD}$ students at varying levels of completion. There was a mix of part time and full-time students from a variety of discipline backgrounds including health sciences, sciences, commerce and humanities. The supervisors were experienced and were from humanities and sciences.

\section{Data sources}

Data were collected using a 3-tier participative drawing process (Wetton \& McWhirter, 1998). This strategy involved a series of two or three interview/discussions, along with participant-made drawings, which formed the focus of the interview/discussions.

This strategy generated two sources of data - interview transcripts and participant drawings - and involved the following (3-tier) phases:

1. Initial semi-structured interview/discussion to ascertain information about participants' backgrounds and other details they saw relevant to share. In addition, 
they were asked about their use of ICT generally as well as within the doctoral process. It was a chance for the researchers to gain some understanding of participants' views and practices in relation to ICT and their doctoral/supervision journeys.

2. Participant drawing. The participants were asked to make a drawing in their own time and before the second interview/discussion. Guidelines for the drawing suggested that they think of a way to illustrate their research process first, then to add onto the drawing any ICT (such as devices, websites, programmes, applications) that they make use of in the process.

3. Follow-up interview/discussion. During this phase, each participant was asked to explain the drawing's features and how it made sense in terms of the project he or she was undertaking. This included discussion about how their supervision was working, how they worked with supervisors, and how the ICT they had included in the drawing worked within the process. They were also asked about elements that were not in the drawing, for example, certain ICT or activities that might have appeared in a typical account of a doctoral research process but were not included.

All interview/discussions were audio recorded and transcriptions of the recordings were returned to the participants for checking. The drawings were scanned and stored electronically.

\section{Analysis}

In line with the interpretive approach that framed and governed our study, the data were analysed shortly after being gathered. Analysis of the data contributed to the development of ideas about participants' perceptions, and these were refined progressively across the instances that researchers met with participants. Perceptions were thus checked, rechecked and refined against each data set.

This iterative and inductive approach (Thomas, 2006) involved thematic analysis (Silverman, 2001) and the capture of major and common ideas (Mayring, 2000) expressed by participants about how ICT are perceived and used in doctoral research processes. This approach helped to operationalise a process of coconstruction between researchers and participants. Through checking, rechecking, refining and confirming, the researchers were able to articulate their understanding of participant perceptions that matched participants' expressed thoughts.

The outcome of the analysis process was four assertions concerning ways the students perceived and understood ICT within doctoral study. Because there were only two supervisor participants, the data from the supervisors served to support the assertions we were more confidently able to make about student perceptions.

\section{Research approach, quality assurance conditions and context}

Despite the (what might be argued, small) number of volunteer participants who showed interest in, and committed themselves to, this study (i.e., no drop-outs or selection being made from a pool), it is worth noting that the researchers worked with each participant over an extended period of time (prolonged engagement), focused on investigating and gathering identifiable, as well as documentable, aspects of the participants' 
ICT understandings and practices (persistent observation), and employed analysis techniques that incorporated peer debriefing, member checking, and fair presentation of assertions (Guba \& Lincoln, 1989).

The aim was to unlock and identify views of reality held by the participants. The empirical evidence was used to help develop commentary and critique of the phenomenon which was the focus of the study (i.e., ICT use), including what the phenomenon is and how it occurs/is enacted/revealed in a particular context (viz., in doctoral research). This was, therefore, a different kind of study from one that might commence with a hypothesis, which would be concerned more with objectivity, explanation and testable propositions. In short, the methods employed in the current study fitted the intention to solve a "puzzle" about a phenomenon in relation to a particular context.

As this study involved human participants, ethical approval was gained through the institutional processes. This approval (University of Otago Human Ethics Committee reference number D17/414 and Victoria University of Wellington, Ethics Committee reference number 0000023415) enabled data collection methods described in the previous section to be carried out for any doctoral students and supervisors who volunteered to participate in this study. Ethical consent, use and care of the data as well as the ethical treatment of students and staff as participants were integral to the research design, planning and implementation of the whole study.

\section{Findings and discussion}

The four assertions are now presented. Each assertion is described and quotations from the interview/discussions along with examples of drawings from the student participants are used to illustrate aspects of each assertion.

Assertion 1: ICT are impartial tools; it does not matter how ICT are used, because the endpoint, that is, thesis completion, is the justification. ICT and people are separate and separated entities.

Students talked about how they worked on their thesis document and on the process of the study they were undertaking. Comments focused on various ICT being used and often on skills needed in order to use them. Some students expressed the view that ICT were tools, separate from the project and the person involved, to be used to achieve an endpoint. For example,

So long as it's formatted - it shouldn't matter - that's their [editors'] responsibility, not mine.

There's probably a bit more about Zoom [web conferencing application] I could learn but again for me unless it's a problem, I'm not going to go looking for it... not just for the sake of it at the moment.

Motivation to achieve an outcome was a focus of comments that support this assertion. For many participants, the aim to complete the study and write a thesis was, naturally, a large driver for how they were managing their study. Time was precious, and they would do what they had to do to reach their goal. To be motivated to learn about a new ICT, there needed to be a purpose that sharply focussed on achieving that end. 
If the technologies are suddenly not available] I'm happy to sit down with a typewriter and learn it... If I'm not driven, I won't bother.

This focus is illustrated in Fig. 1. The drawing shows clearly identified components that make up major elements within the stages of producing the research for the thesis. ICT are listed in relation to those components.

Supervisors too, tended to focus on thesis production rather than on the process of producing a thesis that includes the use of ICT (i.e., as opposed to their very clear and explicit focus on the research process). An example illustrating this is:

Generally, people think the standard of the people getting or earning a $\mathrm{PhD}$ is that this person should be an independent researcher. [But no] After all, we only examine a particular thesis [and] there are lots of inputs from supports and supervision from supervisors.

In summary, this assertion focusses strongly on the experience of doctoral study being about getting the project done within a research journey that gives minimal regard to the affordances of ICT. ICT are framed as necessary but also fraught, especially due to the effort and time that draw attention away from the primary goal.

Assertion 2: ICT are tools or mechanisms that prompt active thought on practices with respect to planning and managing thesis writing and project execution. ICT and individuals work alongside each other.

Views that expressed notions of there being a close interactive relationship between students and ICT came through in several of the discussions with the participants. The focus on achieving goals and endpoints was strong, but the expression of how to

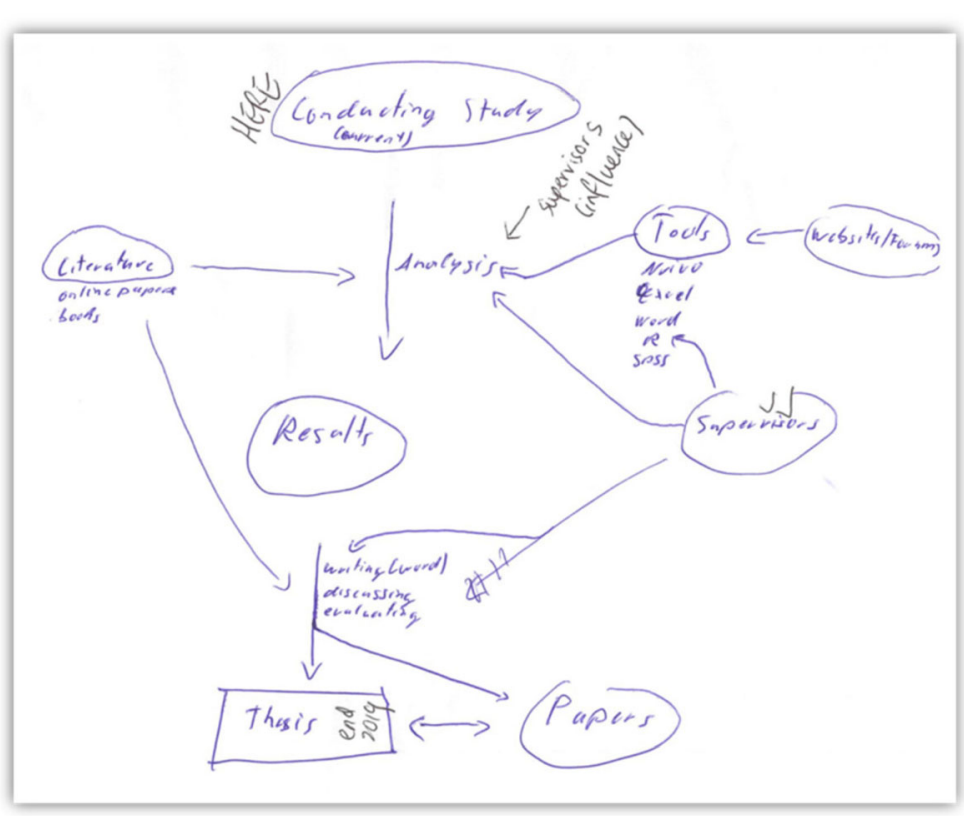

Fig. $1 I C T$ and people are separate and separated entities 
achieve those goals, capitalising upon the affordances that ICT present, was different from the way views were expressed in relation to Assertion 1.

On a simple level, this student describes the checking he did when weighing up the merits of a piece of software to meet his needs.

I normally do a trial version... have a play with it. And if I think they are useful then I might try it on a project. And if then I feel it's definitely worth investing... then I'll go buy it.

Others simply liked to explore, to see whether there was potential in any ICT they encountered, as in,

Sometimes I just like playing with stuff to see what they can do and then if they tick my boxes then I keep them and if they don't, I move on. So it's more kind of 'search and discover' than kind of looking for something, you know.

Describing a deeper level of activity, a degree of critique and active reflection were indicated by another student when he said,

...we tried an electronic version of putting together a programme for a New Zealand conference and I was surprised how long it took us. Whereas in the past I've worked with [colleagues] and we've just moved pieces of paper around on the floor for abstracts and we were done really quickly.

These sentiments are well-captured in Fig. 2. Here, the focus is on experimenting with ICT rather than the research process. The process of working things out to suit the individual is foregrounded.

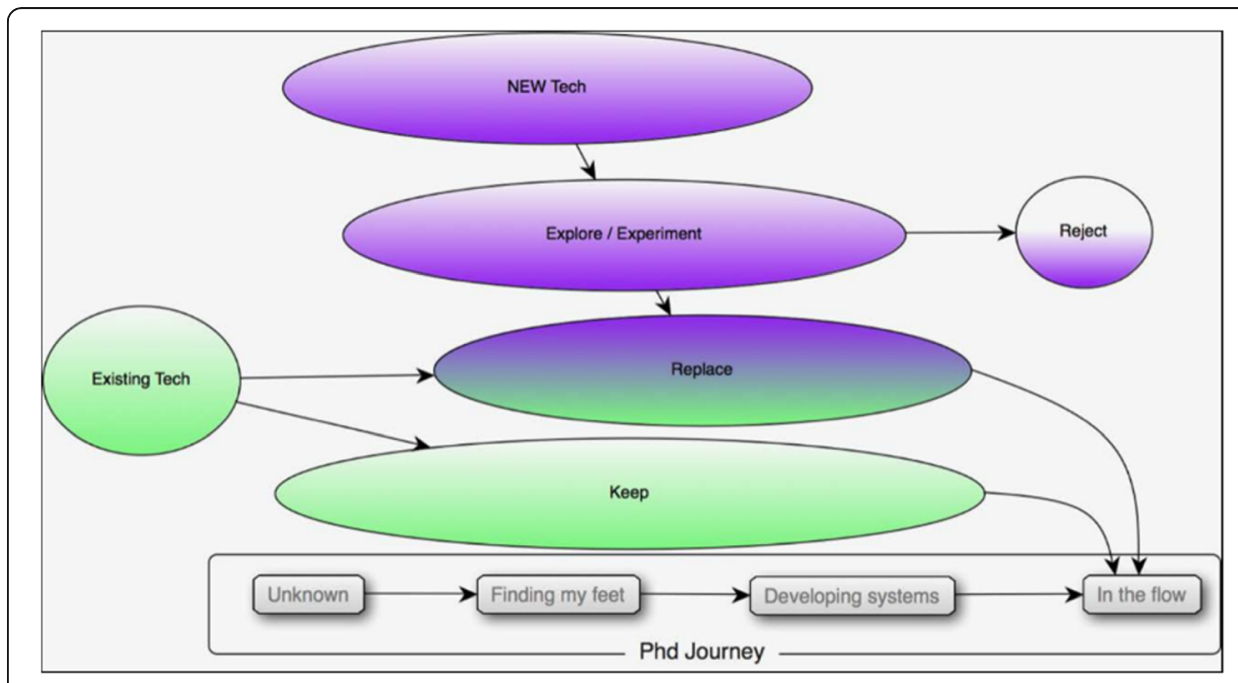

Fig. 2 ICT and individuals work alongside each other 
Whereas Assertion 1-type expressions presented effort in a generally negative light, Assertion 2-type expressions couched effort as an assumed part of learning something new. There was a sense expressed in comments that there will be a way to manage the "problem" to be solved, which then generated the necessary motivation to engage effort. For example,

You just know what you know when you start off; when you're unsure about what you need to do. There's a bit of a barrier in front of you. It feels a bit intimidating and overwhelming, and then you get into it and it just works. And you just kind of put all the pieces together and get something out at the end.

There was a sense that supervisors' perspectives of ICT might support this assertion too. For instance,

[ICT are] integral to everything now - there's no such thing as doing it without [them] anymore - these are the tools with which we do all the things we do.

In summary, this assertion captures the views of students who engage actively in making decisions about which, how and why they incorporate ICT into doctoral research practices.

Assertion 3: Knowing about ICT is only part of the thinking; what is more important is getting the "flow" right. ICT and the individual are in a complementary partnership.

Perhaps prompted by the nature of the drawing task, which was to illustrate how ICT fitted within the whole process of doctoral study, several students described the challenges to bringing everything together into one process made up of many parts, sections and subsections. One participant focussed on her "workflow" in order to manage the multiple documents, tasks and schedule involved in her doctoral research journey.

What systems do I use, what's my workflow? So, I actually spent some weeks looking at ... ideas from other PhD students about their workflows and how they manage it.

Similar to Assertion 2-type comments, 'getting one's flow right' involved exploration and an amount of reflective decision-making. For example,

So I did a play around with that [ICT] and found it was quite useful ... So I'm trying to be quite disciplined about when I've got a document, entering it at the time, reading an article, throw in heaps of tags rather than not ...And I simply keep a note, cross referencing to the actual articles. I like to have the articles and for some key ones I like to make a note. So, if it's a seminal paper that I know I'll be referring back to.

Thus, students talked about how hard they worked to set up routines and processes to enable them to manage time and their research projects. As in the above excerpts, 
they referred to categorising documents, searching for resources, undertaking analysis, managing data, and producing the thesis itself.

In working out one's system or flow, this student highlighted the need to know about the affordances of ICT and how others had made use of them.

...you do need to know a bit about each of the individual ... capabilities of the different systems to know what's even possible... but alongside that you're kind of reading other people's ideas of how they did it, and you think that bit might work for me oh, but that bit won't... so then you can kind of mix and match a bit.

The drawing in Fig. 3 highlights the "flow". Absent of all words, this illustration draws attention to the movement of ideas, thoughts, processes and actions, from a number of different points but all ultimately converging or contributing to the one path.

There was a hint that at least one of the supervisors saw the need for a workflow in this same vein: "So long as [the students are] happy with what they're using - they should use 'a' system,"

In summary, this assertion highlights that what is important with respect to ICT and the doctoral process is how it all comes together within one's flow. That flow incorporates active effort on the part of the individual in finding ICT and practices that suit the individual's approaches as well as their project demands.

Assertion 4: ICT are not neutral; there is a two-way interaction between technologies as artefacts and the use of them to achieve ends. ICT and the person are intricately linked through multiple active, practical, goal-oriented connections.

This assertion draws attention to the nature of technology as a phenomenon; that technology is not an impartial tool that has no influence on the way humans act and react. This assertion presents ICT as an artefact of technological design activity; as a source of improving efforts to achieve an endpoint; but also as an influencer and even determiner of the thinking and practices of the person interacting with the ICT (e.g., Baird, 2002).

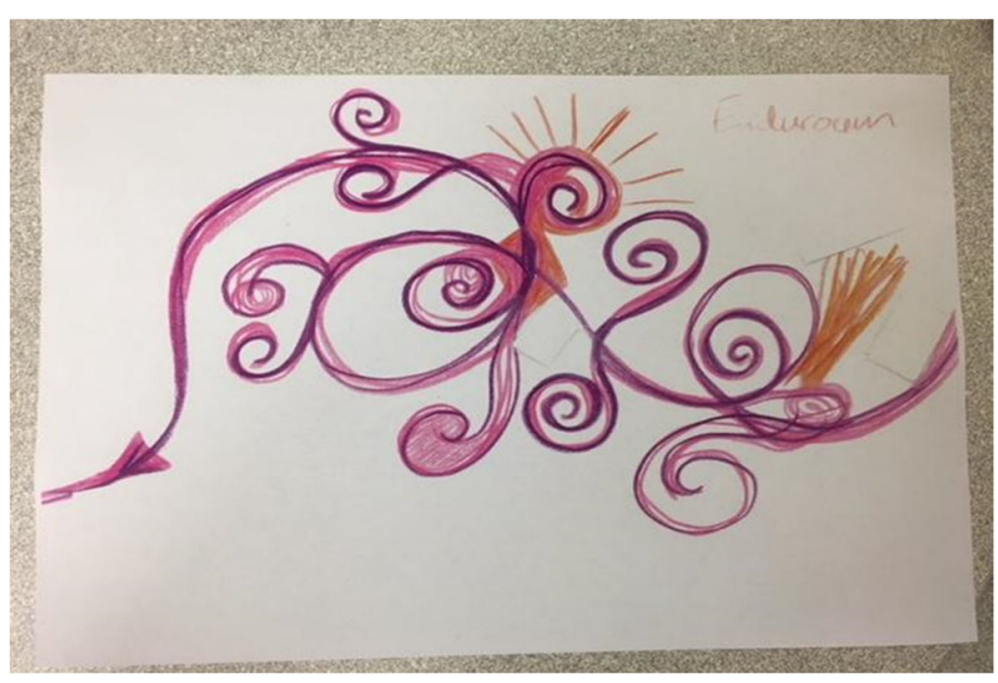

Fig. $3 I C T$ and the individual are in a complementary partnership 
On what could be argued a superficial level, this student noted some active connection between the person and the software application, beyond simple use, when he commented:

I think it goes both ways, the product has to be intuitive and you've got to have a little bit of inclination to try out different things.

Others went beyond the superficial to describe more in-depth relationships between themselves and the ICT they were using. When discussing her use of software to help her manage her project and her time, this student talked about how the ICT she was using supported and enhanced her thinking.

Using the application] really changed the way I started to think about [my research]. I started to be less worried about the big overwhelming long term stuff that was out there and just think, okay, this week, what am I going to do this week, how am I going to be really efficient and targeted, and I think that really helped me.

Following is another example of how ICT helped solve a problem while simultaneously having an influence on behaviour; in this instance with organising notes, ideas and documents.

“... and it's the same with my note-taking because [the programme] that I use has a similar sort of functionality that it can search text that you've written but also search notes and PDF docs and those kind of things, so it means that when you've had a random thought and put it somewhere you can find it again. Which is huge for me, so I guess that ... the power of the search engine is probably the thing that drove me to become paperless, so it helps me to organize myself much better. ... filing paper is a skill that I have not mastered whereas filing digital stuff is not as important because you can always just find it again.

Figure 4 illustrates this intricately intertwined interactivity among person, purpose, project, ICT and outcomes.

While we did not find strong evidence for supervisors' thoughts about this integrated and embedded notion of ICT, one supervisor did note "I could probably build them into my system, but I just never have".

In summary, Assertion 4 highlights the integral role that ICT can be perceived to play in doctoral research processes. This is more than the working-alongside connection illustrated by Assertion 2 and the complementary partnership characterised by Assertion 3 .

Assertions 1 and 2 highlight that individuals hold assumptions about, and have expectations of, ICT use; and those expectations and assumptions influence and determine their judgements about ICT and their use of ICT. The assertions point to connections between perceptions and practices. Assertion 1 describes a perception that ICT are separate from the person and the task-at-hand, while Assertion 2 presents a perception in which the person and the ICT are working alongside each other in harmony or at least in a loose partnership. Both assertions focus on endpoints, but the endpoints vary according to the perception of where ICT fit into 


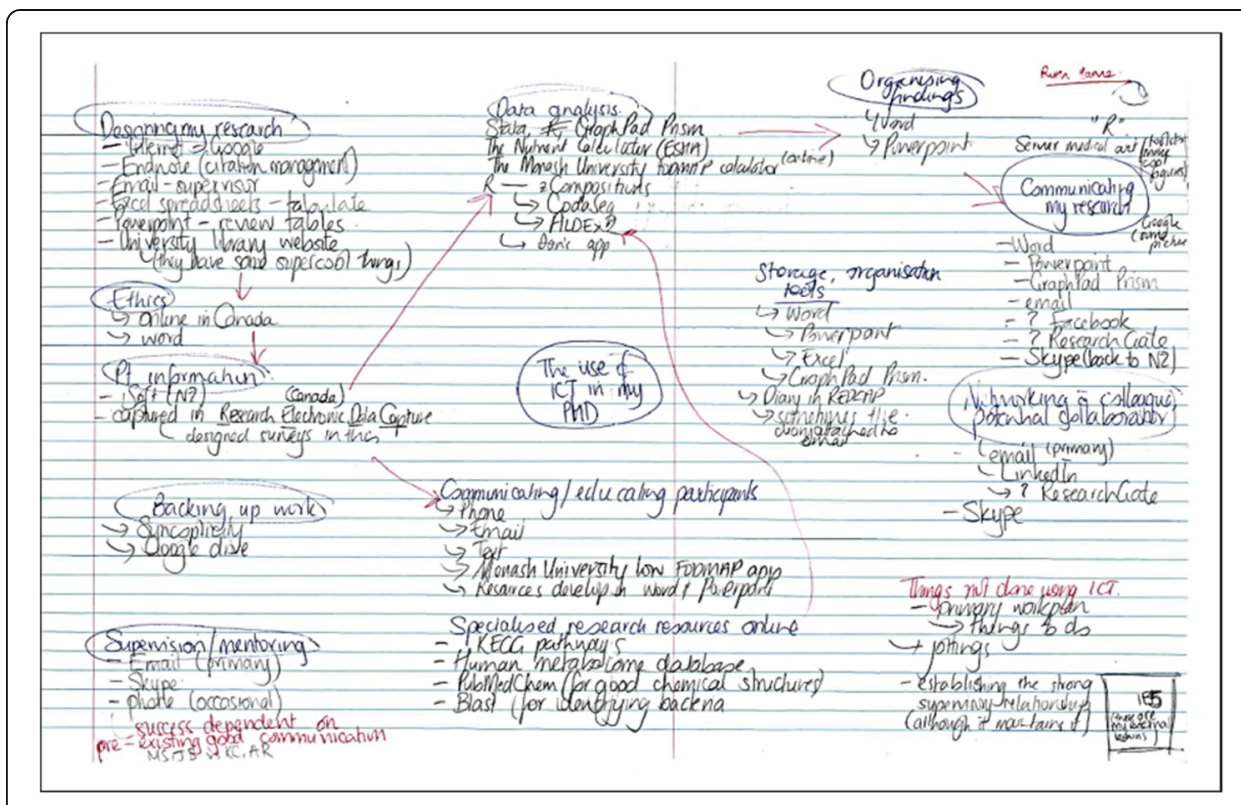

Fig. 4 ICT and the person are intricately linked through multiple active, practical, goal-oriented connections

the journey towards their achievement. For Assertion 1-type expressions, there is one major endpoint. For Assertion 2-type expressions, there are multiple, shorterterm endpoints that build towards achieving the major goal of completing the thesis.

Building on Assertions 1 and 2 are Assertions 3 and 4, which highlight what may be argued as more complex levels of perceiving and working with ICT. Both assertions give some focus to inter-connections, where people and ICT partner or collaborate. Assertion 3 depICT a perception that is about complementarity; where ICT affordances are seen as worthwhile when they support and enhance the work of the individual in ways that make sense to that individual. Assertion 4 builds on Assertion 3 by bringing to light the relationship in which the person alters and changes thinking or practices because of the influence that ICT affordances can have. No evidence was found to support a possible additional claim that as well as ICT causing individuals to alter and modify thinking and behaviours due to their existence, ICT, in turn, are perceived to be able to alter their ways of responding to the people who use them. This is not out of the realms of possibility of course, with ICT increasingly being designed and built to be able to respond to users' needs.

It is also worth mentioning that the 'types' of ICT and the extent of their use by the participants was not the focus of this study. However, the findings suggested that the participants' ICT use, regardless of their PhD phase and broad discipline background, might have reflected their inability to realise the advantages of learning how to use current ICT-related devices, tools, and applications to enhance the process of undertaking their doctoral research. The evidence that emerged in this study indicated that participants' perspectives of ICT determined their adoption practices in general (i.e., as illustrated through the four assertions). The boarder higher education context including 
the specific institution and supervisors, might have neglected the explicit support of PhD students' ICT capability development in this process.

In addition, while there is no similar study being found thus far, the insights gained from this study are actually similar to the findings in the research studies into the role of ICT in undergraduate education (Butson \& Sim, 2013; Sim \& Butson, 2013, 2014). Results in those studies, demonstrated students' low levels of ICT use, may be an indication that digital devices and digital tools do not play a significant role in daily study practices. Researchers such as Esposito, Sangrà \& Maina (2013) also show that the PhD students' learning to become researchers in the digital age is much more complex than is often suggested (e.g., the skills of Prenksy (2001) "digital natives"). Becoming a researcher involves developing a complex set of knowledge, intellectual abilities, techniques and professional standards. The Researcher Development Framework (Careers Research and Advisory Centre (CRAC), 2010) illustrates one useful attempt at mapping out that complexity. It could be that both students' and supervisors' adoption of ICT for academic purposes has been overshadowed or taken for granted as a consequence of their advanced academic level.

\section{Implications}

The four assertions can be used to provide some guidance to those supporting and participating in doctoral research processes. Students and supervisors do possess a vast array of skills, knowledge and abilities. They have a variety of experiences as well as varying reasons and levels of motivation. Their skills and capacity to make use of ICT to support their roles in the research process vary as well. The assertions that have emerged from this study will inform the planning for support activities to enhance supervisors' and students' professional development, whatever their background and needs.

Depending on the perceptions held about ICT and the relationship between ICT and the person in the context of the task and its goals (i.e., the doctoral study) within the doctoral research process as depicted in the four assertions, ICT tend to be seen as a challenge, a change or an opportunity. In the context of ICT use, doctoral students and supervisors may:

- assume that if they do not already know how to use something it is not worth learning or exploring as that learning brings with it risk to quality, efficiency and effectiveness of the doctoral research process; and/or.

- assume that students will work out the place that ICT play within the research process for themselves.

The findings of this study suggest the need to.

- challenge existing ICT knowledge and skill, and to support acceptance of the need to change practices;

- teach technological thinking, to enable choice and decision making about ICT;

- embed ICT into practices in meaningful ways to suit individual and project needs;

- highlight (explicit) responsibilities about thinking and planning skills with respect to making the best use of ICT, to ensure efficiency and effectiveness; 
- realise that the research process is as much about how it happens as what happens;

- recast assumptions about the doctoral research process to embed ICT within it;

- reflect on the meaning of effectiveness and efficiency in the context of doctoral research; and the effects of ICT in supporting and facilitating them;

- understand that there is a link among ICT thinking and practice: using ICT can enhance or raise ideas that were never thought of before.

\section{Conclusion}

This study explored perceptions of doctoral supervisors and students of the role and place of ICT in supervision and study. It generated four assertions characterising those perceptions the relationships among people, ICT and the task-at-hand, that is, the supervised research process. As Castañeda and Selwyn (2018) argue, it is important that we have an active commitment to 'think otherwise' about how ICT might be better implemented across higher education settings" (p. 8). We should not assume that ICT are not important enough to let them fade into the background as they become normalised, without questioning the interrelationships that are happening between the person and the ICT. In the doctoral research setting, as one example of a higher education context, ICT do have a role to play. They cannot and should not be ignored. But seeing ICT in relationship to the person and to the setting is essential.

This project has provided insights into the doctoral students and supervisors' perceptions of the roles played by ICT during doctoral research process. There are complex human factors, including assumptions, attitudes and conceptions about academic practices, influencing and determining perspectives as well as how ICT are incorporated into doctoral research process, behaviours and practices. Just as Kandiko and Kinchin (2012) argue that supervision cannot be looked at in the absence of the research work in which it occurs, we argue that doctoral students' understanding and use of ICT cannot be considered independently of their research work; and that work includes relationships with their project, their supervisors, within the context of the institution, and with the ICT they do and could engage with.

Directly associated with the outcomes of this study, future studies and further exploration could focus on:

- ICT use by larger and more diverse groups of doctoral students from a range of fields within discipline areas at institutions outside New Zealand;

- building on the findings in order to determine how intensity of ICT use might change for students across the course of their candidature, and in relation to the nature of their research projects;

- the role of supervisors, academic departments, and institutions in supporting and enhancing students' practices and beliefs about ICT in research processes;

- the ways in which supervisors engage ICT in their daily academic practices, with a view to exploring how, or if, their ICT use is an influence on PhD students' beliefs and behaviours in using ICT.

Studying ICT in these directions could offer fresh perspectives and opportunities to think differently and reveal an active way of understanding the role of ICT in doctoral education. 


\section{Acknowledgements}

We thank the students and supervisors who shared their reflections and willingly engaged with us in this project.

\section{Authors' contributions}

The authors are responsible for the entire project that is reported in this paper. The writing of the manuscript was led by the first author in collaboration with the second author. The authors read and approved the final manuscript.

\section{Funding}

We acknowledge the support of Ako Aotearoa, The National Centre for Tertiary Teaching Excellence, New Zealand through its Regional Hub Project Fund (RHPF), and the support of our institutions, University of Otago and Victoria University of Wellington.

\section{Availability of data and materials}

These are not available for open access as their access is bound by the ethical agreement approved by the two institutions and made with the participants in the study.

\section{Competing interests}

The authors declare no competing interests.

\section{Author details}

${ }^{1}$ Distance Learning, University of Otago, Dunedin, New Zealand. ${ }^{2}$ Centre for Academic Development, Victoria University of Wellington, Wellington, New Zealand.

Received: 2 February 2020 Accepted: 5 May 2020

Published online: 10 September 2020

\section{References}

Aghaee, N., Jobe, W. B., Karunaratne, T., Smedberg, Å., Hansson, H., \& Tee, M. (2016). Interaction gaps in PhD education and ICT as a way forward: Results from a study in Sweden. International Review of Research in Open and Distance Learning, 17(3) Retrieved from https://search.proquest.com/docview/1805463156?accountid=14700.

Åkerlind, G., \& McAlpine, L. (2017). Supervising doctoral students: Variation in purpose and pedagogy. Studies in Higher Education, 42(9), 1686-1698. https://doi.org/10.1080/03075079.2015.1118031.

Baird, D. (2002). Thing knowledge: Function and truth. Techné: Research in Philosophy and Technology, 6(2), 96-105. https:// scholar.lib.vt.edu/ejournals/SPT/v6n2/.

Butson, R., \& Sim, K. N. (2013). The role of personal computers in undergraduate education. International Journal of Digital Literacy and Digital Competence, 4(3), 1-9. https://doi.org/10.4018/ijdldc.201307010.

Careers Research and Advisory Centre (CRAC) (2010). Researcher development framework, (pp. 1-22) Retrieved from https:// www.vitae.ac.uk/vitae-publications/rdf- related/researcher-development-framework-rdf-vitae.pdf.

Castañeda, L., \& Selwyn, N. (2018). More than tools? Making sense of the ongoing digitizations of higher education. International Journal of Educational Technology in Higher Education, 15(22), 1-10. https://doi.org/10.1186/s41239-018-0109-y.

Cotterall, S. (2011). Doctoral students writing: Where's the pedagogy? Teaching in Higher Education, 16(4), 413-425. https:// doi.org/10.1080/13562517.2011.560381.

Dowling, R., \& Wilson, M. (2017). Digital doctorates? An exploratory study of PhD candidates' use of online tools. Innovations in Education and Teaching International, 54(1), 76-86. https://doi.org/10.1080/14703297.2015.1058720.

Erickson F. (2012). Qualitative research methods for science education. In Fraser, B., Tobin, K., \& McRobbie, C. J. (Eds.), Second international handbook of science education. (Springer International Handbooks of Education, Vol. 2, pp. 1451-69). Dordrecht: Springer. https://doi.org/10.1007/978-1-4020-9041-7_93.

Esposito, A., Sangrà, A., \& Maina, M. (2013). How Italian PhD students reap the benefits of instiutional resources and digital services in the open web. Proceedings of the International technology, education and development (INTED) conference, pp. 6490-6500. Valencia: Spain. ISBN: 978-84-616-2661-8.

Guba, E. G., \& Lincoln, Y. S. (1989). Fourth generation evaluation. Newbury Park: Sage.

Kandiko, C. B., \& Kinchin, I. M. (2012). What is a doctorate? A concept-mapped analysis of process versus product in the supervision of lab-based PhDs. Educational Research, 54(1), 3-16. https://doi.org/10.1080/00131881.2012.658196.

Lee, A. (2008). How are doctoral students supervised? Concepts of doctoral research supervision. Studies in Higher Education, 33(3), 267-281. https://doi.org/10.1080/03075070802049202.

Mahmood, K. (2016). Do people overestimate their information literacy skills? A systematic review of empirical evidence on the Dunning-Kruger effect. Communications in Information Literacy, 10(2), 199-212. https://doi.org/10.15760/comminfolit. 2016.10.2.24.

Marshall, S., \& Shepherd, D. (2016). E-learning in tertiary education. Highlights from Ako Aotearoa projects. Wellington: Ako Aotearoa https:/akoaotearoa.ac.nz/download/ng/file/group-4/e-learning-in-tertiary-education-highlights-from-akoaotearoa-research.pdf.

Mayring, P. (2000). Qualitative content analysis. Forum: Qualitative Social Research, 1(2) Retrieved from https://search.proquest. com/docview/867646667? accountid $=14700$

Nichols, M., Anderson, B., Campbell, M., \& Thompson, J. (2014). An online orientation to open, flexible and distance learning Ako Aotearoa and the distance education Association of New Zealand (DEANZ). https://ako.ac.nz/knowledge-centre/anonline-orientation-to-open-flexible-and-distance-learning/.

Prenksy, M. (2001). Digital natives, digital immigrants, part II. Do they really think differently? On the. Horizon, 9(6), 1-6.

Silverman, D. (2001). Interpreting qualitative data. 2nd Ed. London: Sage.

Sim, K. N., \& Butson, R. (2013). Do undergraduates use their personal computers to support learning? Procedia - Social and Behavioral Sciences, 103, 330-339. https://doi.org/10.1016/j.sbspro.2013.10.341. 
Sim, K. N., \& Butson, R. (2014). To what degree are undergraduate students using their personal computers to support their daily study practices? IAFOR Journal of Education, 2(1), 158-171 Retrieved from http://search.ebscohost.com/login. aspx?direct=true\& $\mathrm{db}=$ eric $\& A N=E J 1080348 \&$ site $=$ ehost-live.

Stensaker, B., Maassen, P., Borgan, M., Oftebro, M., \& Karseth, B. (2007). Use, updating and integration of ICT in higher education: Linking purpose, people and pedagogy. Higher Education, 54, 417-433. https://doi.org/10.1007/s10734-0069004-x.

Thomas, D. R. (2006). A general inductive approach for analyzing qualitative evaluation data. American Journal of Evaluation, 27(2), 237-246. https://doi.org/10.1177/1098214005283748

Wetton, N. M., \& McWhirter, J. (1998). Images and curriculum development in health education. In J. Prosser (Ed.), Imagebased research: A sourcebook for qualitative researcher, (pp. 263-283). London: Falmer Press.

Zhou, E., \& Okahana, H. (2019). The role of department supports on doctoral completion and time-to-degree. Journal of College Student Retention: Research, Theory \& Practice, 20(4), 511-529. https://doi.org/10.1177/1521025116682036.

\section{Publisher's Note}

Springer Nature remains neutral with regard to jurisdictional claims in published maps and institutional affiliations.

Submit your manuscript to a SpringerOpen ${ }^{\circ}$ journal and benefit from:

- Convenient online submission

- Rigorous peer review

- Open access: articles freely available online

- High visibility within the field

- Retaining the copyright to your article

Submit your next manuscript at $\boldsymbol{\nabla}$ springeropen.com 